\title{
EFEITO DA SECAGEM E DE DIFERENTES TEMPERATURAS NA GERMINAÇÃO DE SEMENTES DE Protium widgrenii Engler.
}

\author{
Effect of the drying and different temperature on germination of \\ Protium widgrenii Engler seeds
}

\author{
Marina Seiffert ${ }^{1}$, Amauri Alves Alvarenga ${ }^{2}$, Renato Mendes Guimarães ${ }^{3}$ \\ Evaristo Mauro de Castro ${ }^{3}$, Maria das Graças Cardoso ${ }^{3}$, Renato Paiva ${ }^{3}$, \\ Sara Dousseau ${ }^{4}$, Carlos Vinicio Vieira ${ }^{4}$
}

\begin{abstract}
RESUMO
Protium widgrenii Engler (Burseraceae) conhecida como almecega-vermelha, é uma espécie nativa, ocorrendo desde Minas Gerais até o Rio Grande do Sul, em quase todas as formações florestais e considerada de grande utilidade para plantios mistos destinados à recomposição de áreas degradadas de preservação permanente. Objetivou-se com este trabalho estudar o efeito da dessecação e de diferentes regimes térmicos sob a germinação de suas sementes. Foram utilizadas sementes com umidade inicial de $51 \%$ e sementes dessecadas a $13 \%$ de umidade, as quais foram submetidas a um pré-tratamento a frio $\left(5^{\circ} \mathrm{C} / 24\right.$ horas $)$ e, posteriormente distribuídas em três rolos de papel germtest, em câmaras de germinação do tipo BOD e em diferentes temperaturas $\left(15 ; 25 ; 35^{\circ} \mathrm{C}\right.$ constantes e escuro e, $30-20^{\circ} \mathrm{C}$, D/N.). Sementes com $51 \%$ de umidade apresentaram maior germinação a $25^{\circ} \mathrm{C}$ e menor a $35^{\circ} \mathrm{C}$, com menor IVG a $15^{\circ} \mathrm{C}$ e o maior a $25^{\circ} \mathrm{C}$. Com a dessecação a $13 \%$ de umidade, as sementes a $15^{\circ} \mathrm{C}$ apresentaram menores IVG e germinação. A porcentagem final de germinação a $15^{\circ} \mathrm{C}$ foi maior em sementes com $51 \%$ de umidade e IVG menor a $25^{\circ} \mathrm{C}$ em sementes dessecadas.
\end{abstract}

Termos para indexação: Sementes, germinação, dessecação, temperatura.

\begin{abstract}
Protium widgrenii Engler (Burceraceae) known as "almecega-vermelha", is a native species that occurs in many forest formations Minas Gerais to Rio Grande do Sul and is considered usefull in mixed plantings used for restoration of depleted areas of permanent preservation. The objective of this work was to study the effect of dessecation and the different termic regimes on seed germination. Were used seed with initial humidity of $51 \%$ and seeds dessecated until $13 \%$ humidity, were submitted to a cold pretreatment $\left(5^{\circ} \mathrm{C} / 24\right.$ hours) and distributed in three rolls of germtest paper and maintained in a germination chamber, type BOD under different temperatures $\left(15,25,35^{\circ} \mathrm{C}\right.$ constant, dark and $30-20^{\circ} \mathrm{C}$, Day/Night. Seeds with $51 \%$ humidity presented higher and lower germination at $25^{\circ} \mathrm{C}$ and $35^{\circ} \mathrm{C}$ and higher and lower IVG at $25^{\circ} \mathrm{C}$ and $15^{\circ} \mathrm{C}$, respectively. Using dessecation at $13 \%$ humidity, the seeds at $15^{\circ} \mathrm{C}$ showed the lowest IVG and germination. Final germination percentage at $15^{\circ} \mathrm{C}$ was higher in seeds with $51 \%$ humidity and lower IVG at $25^{\circ} \mathrm{C}$ in desseccted seeds.
\end{abstract}

Index terms: Seeds, germination, dessecation, temperature.

(Recebido para publicação em 26 de novembro de 2003 e aprovado em 22 de abril de 2005)

\section{INTRODUÇÃO}

Protium widgrenni Engler (Burseraceae), conhecido popularmente como almecega-vermelha, é uma espécie que ocorre em quase todos os ecossistemas florestais (cerrado e mata ciliar), desde Minas Gerais até o Rio Grande do Sul (KLEIN, 1978; VARANDA, 1995). A importância da espécie é vista no plano ecofisiológico, podendo ser utilizada na recomposição de áreas degradadas e de preservação permanente em composições mistas (OLIVEIRA FILHO et al., 1994).

Não foram encontradas na literatura informações relativas à propagação de Protium widgrenni Engler.
Entretanto, para Protium heptaphyllum (Aubl.) March e Protium spruceanum (Benth.) Engler, a taxa de germinação geralmente é baixa, constituindo um grande entrave para a propagação e posterior produção de mudas em larga escala e, segundo Lorenzi (1992), o desenvolvimento das plantas no campo é considerado de moderado a rápido.

A germinação é considerada um dos mais importantes estádios do biociclo vegetal, caracterizada por processos fisiometabólicos de natureza complexa, que levam à retomada do crescimento do eixo embrionário, culminando com a protrusão da radícula através do tegumento da semente BEWLEY \& BLACK, 1994).

${ }^{1}$ Mestranda em Agronômia/Fisiologia Vegetal - Universidade Federal de Lavras/UFLA - Cx. P. 3037 - 37.200-000 - Lavras, MG.

${ }^{2}$ Professor Titular do Departamento de Biologia - Universidade Federal de Lavras/UFLA - Cx. P. 3037 - 37.200-000 - Lavras, MG - amauriaa@ufla.br ${ }^{3}$ Professores Adjunto dos Departamentos de Agricultura, Biologia e Química - Universidade Federal de Lavras/UFLA - Cx. P. 3037 - 37.200-000 - Lavras, MG ${ }^{4}$ Graduandos em Agronômia - Universidade Federal de Lavras/UFLA - Cx. P. 3037 - 37.200-000 - Lavras, MG 
Por ser considerada uma fase crítica no contexto geral do desenvolvimento vegetal, inúmeros estudos têm sido conduzidos abrangendo diferentes aspectos fisiológicos e bioquímicos da germinação, associados à dormência, temperatura, luz e reguladores de crescimento (BEWLEY \& BLACK, 1994; HERMANSEN et al., 2000; LABOURIAU et al., 1995; NAIDU et al., 2000; PANDEY et al., 2000; PATANÈ, 2000). O estudo da ecofisiologia da germinação permite a compreensão mais precisa dos processos que regulam a longevidade das sementes no solo e o estabelecimento das plantas em condições naturais (VÁZQUEZ-YANES \& OROSCO-SEGOVIA, 1987).

O processo de embebição de sementes é o primeiro passo na sequiência de eventos da germinação, o que permite a retomada das atividades metabólicas da semente, culminando com a protrusão radicular. O conhecimento do comportamento do processo de embebição das sementes é de importância fundamental, pois, pode permitir a identificação da presença ou ausência de dormência tegumentar, facilitando a adoção de tratamentos pré-germinativos, tais como condicionamento osmótico, pré - hidratação, bem como uso de fitorreguladores (PINHO et al., 2003).

Em relação à temperatura, essa constitui num dos principais fatores de controle da germinação de sementes na natureza, sendo o conhecimento das temperaturas cardeais de fundamental importância para o entendimento da ocorrência das espécies de plantas (LABOURIAU \& AGUDO, 1987). Inúmeros trabalhos vêm demonstrando ser este um dos fatores responsáveis não somente pela velocidade de germinação como também pelo percentual final de germinação (GODOI \& TAKAKI, 1996; TIGABU $\&$ ODEM, 2001). Sementes de diferentes espécies e classificação ecológica apresentam respostas diferenciais à temperatura do meio de germinação (BENVENUTI et al., 2001; CASTELLANI \& AGUIAR, 2001; RAJPUT \& TIWARI, 2001; TIGABU \& ODEM, 2001).

Sementes utilizadas para a produção de mudas devem ser mantidas íntegras e viáveis, sobretudo quando a semeadura não ocorre imediatamente após a maturação e colheita. Entre as espécies florestais, na maioria das vezes, torna-se difícil preservar a viabilidade e o vigor das sementes; por isso, fatores como temperatura e umidade devem ser considerados durante o armazenamento, visando prolongar a longevidade e a sua viabilidade (ALVARENGA, 1987; CORRÊA, 1997; OLADIRAN \& AGUNBIADE, 2000; RAMOS, 1980). Nesse contexto, a secagem apresenta-se como uma exigência para garantir a qualidade da semente durante o armazenamento. Entretanto, esta deve ser precisa e conduzida de forma criteriosa, em função dos níveis de umidade que a espécie em questão tolera (CARVALHO, 2000).

De acordo com o nível de tolerância dessas sementes à dessecação, elas podem ser classificadas como ortodoxas, recalcitrantes e intermediárias (KRAAK, 1993; ROBERTS, 1973). As sementes ortodoxas podem ser seguramente desidratadas a baixos níveis de umidade, geralmente, em média, a 5\%. De maneira geral, a longevidade das sementes ortodoxas aumenta com a redução do teor de umidade. Sob baixas temperaturas e umidade relativa, as sementes ortodoxas podem ser armazenadas por muitos anos, sem que haja perdas significativas de viabilidade.

As sementes recalcitrantes são sensíveis à dessecação e baixas temperaturas, apresentando, em geral, um alto teor de umidade. Portanto, a longevidade das sementes recalcitrantes é relativamente curta. Em adição, torna-se difícil o estabelecimento de protocolos de armazenamento que venham a proporcionar a manutenção da integridade estrutural e viabilidade dessas sementes (KUNDU et al., 2003; SUN \& LIANG, 2001; VARGHESE \& NAITHANI, 2000; VARGHESE et al., 2002).

Uma terceira categoria de sementes, de comportamento intermediário, pode sobreviver sob secagem moderada, geralmente até um limite de $12 \%$ de umidade. Essas sementes podem ser armazenadas por um tempo razoável, desde que as condições do ambiente e de embalagens sejam bem definidas.

Com este trabalho, objetivou-se estudar o efeito da secagem e de diferentes temperaturas na germinação das sementes de Protium widgrenii Engler, visando desenvolver protocolos de germinação para esta espécie, além de fornecer subsídios para estudos posteriores de armazenamento.

\section{MATERIAL E MÉTODOS}

O presente trabalho foi conduzido no Laboratório de Crescimento e Desenvolvimento de Plantas, Setor de Fisiologia Vegetal, do Departamento de Biologia da Universidade Federal de Lavras, MG.

Frutos de Protium widgrenii foram colhidos na época da dispersão (novembro, 2001), em dez plantas matrizes, localizadas em área de cerrado no município de Lavras, região sul do Estado de Minas Gerais, a 918 m de altitude, latitude $21^{\circ} 14^{\prime} \mathrm{S}$ e longitude $45^{\circ} \mathrm{GRW}$. Posteriormente, os frutos foram transferidos para beneficiamento em laboratório, para a retirada do epicarpo e mesocarpo, selecionando-se apenas aquelas sementes com endocarpo de coloração marrom-escuro. 


\section{Teor de umidade das sementes}

Após o processamento dos frutos, foi determinada a umidade das sementes pelo método da estufa a $70^{\circ} \mathrm{C}$ por 72 horas, utilizando-se três amostras de 10 sementes cada. $\mathrm{O}$ valor percentual de umidade foi obtido com base na média das pesagens das massas fresca e seca das amostras, sendo o teor de umidade calculado pela expressão:

Teor de umidade $(\%)=[($ massa fresca - massa seca $) /$ massa fresca] $\mathrm{x} 100$

\section{Teste de Tetrazólio}

O teste de Tetrazólio foi realizado nas sementes com $51 \%$ de umidade, utilizando-se três repetições de 10 sementes cada. As sementes foram pré-embebidas por 24 horas em água destilada a $5^{\circ} \mathrm{C}$ e posteriormente seccionadas longitudinalmente. Descartou-se cerca de $70 \%$ dessas sementes, cujo embrião encontrava-se ausente, apresentando apenas o tegumento membranáceo. As restantes foram colocadas em pequenos béqueres no escuro a $30^{\circ} \mathrm{C}$, contendo $10 \mathrm{~mL}$ de solução de 2,3,5 trifenil cloreto de Tetrazólio a $0,5 \%$ por 3 horas, devidamente envoltos com papel alumínio. Após o período de exposição, a solução foi drenada e as sementes lavadas em água corrente para posterior avaliação. Foram consideradas viáveis as sementes cujo embrião coloriu-se completamente de rosa-claro.

\section{Efeito da secagem e das temperaturas}

Sementes com umidade inicial de $51 \%$ foram submetidas à secagem sob condições ambientais de laboratório. A umidade e temperatura do ambiente foram registradas com auxílio de um termohigrógrafo, cujos valores registraram, em média, $60 \%$ de umidade relativa (UR) e temperatura de $25 \pm 2{ }^{\circ} \mathrm{C}$. As sementes foram pesadas a cada duas horas, até atingirem peso correspondente a $13 \%$ de umidade. Nas pesagens, foi utilizada uma balança analítica digital com precisão de miligramas, sendo os cálculos realizados de acordo com a fórmula para teor de umidade descrita anteriormente. A testemunha utilizada foi constituída por sementes não submetidas à secagem, com umidade de $51 \%$.

Antes de submeterem-se as sementes a diferentes temperaturas de germinação foi imposto um pré-tratamento determinado por testes preliminares (dados não apresentados), em que estas foram submersas em água destilada por 24 horas a uma temperatura de $5^{\circ} \mathrm{C}$.

Posteriormente a este pré-tratamento a frio, as sementes foram distribuídas em três rolos de papel germtest, colocados em béqueres na posição vertical, contendo uma lâmina de água destilada e cobertos com sacos plásticos para manutenção da umidade. Cada béquer foi em seguida colocado em câmaras de germinação do tipo BOD, em diferentes temperaturas $\left(15^{\circ} \mathrm{C}, 25^{\circ} \mathrm{C}, 35^{\circ} \mathrm{C}\right.$ constantes e no escuro e, ainda um regime de $30-20^{\circ} \mathrm{C}$ sob fotoperíodo de $16 \mathrm{~h}$ ).

Todos os experimentos foram conduzidos seguindo-se um delineamento inteiramente casualizado, em esquema fatorial de 4 × 2 (quatro regimes térmicos com e sem secagem), com três repetições de 50 sementes cada. $\mathrm{O}$ critério para germinação foi a protrusão de $1 \mathrm{~mm}$ de radícula. Foram realizadas contagens diárias, sendo avaliados a porcentagem final de germinação e o índice de velocidade de germinação (IVG) com base apenas nos $30 \%$ de sementes viáveis, ou seja, aquelas que apresentaram embriões completamente formados. A análise estatística foi realizada mediante o uso do programa estatístico SISVAR (FERREIRA, 1999). Os dados de germinação foram transformados em arco seno $(\mathrm{x} / 100)^{0,5}$ e o índice de velocidade de germinação em (x + 0,5) $)^{0,5}$ (BARTLETT, 1936;ZAR, 1999). Foi realizada a análise de variância e as médias foram comparadas pelo teste de Tukey, a 5\% de probabilidade.

\section{RESULTADOS E DISCUSSÃO}

\section{Teste de Tetrazólio}

Pelo teste de Tetrazólio, foi observado que $100 \%$ das sementes mostraram-se viáveis, pois todas elas apresentaram coloração rosa-claro uniformemente distribuído por todo o embrião. $\mathrm{O}$ teste de Tetrazólio é bastante rápido e muito utilizado para estimar a viabilidade em diferentes lotes de sementes, entretanto, ele não leva em consideração as adversidades ambientais, tais com microrganismos, que podem ter ação deletéria sobre a porcentagem final de germinação (KRZYZANOWISKI et al., 1999).

\section{Efeito da secagem e da temperatura}

Na Figura 1, são apresentados os resultados relativos à porcentagem de germinação das sementes sob diferentes regimes térmicos. As sementes apresentaram comportamento diferenciado em relação aos regimes térmicos testados e em função do seu teor de umidade. Sementes com $51 \%$ de umidade apresentaram maior germinação a $25^{\circ} \mathrm{C}(80 \%)$ e menor a $35^{\circ} \mathrm{C}(54 \%)$, enquanto a $15^{\circ} \mathrm{C}$ e $20-30^{\circ} \mathrm{C}$, as porcentagens de germinação não diferiram dos demais regimes térmicos, sendo ambos, $67 \%$. Após a dessecação ao nível de $13 \%$ de umidade, as sementes apresentaram menor germinação a $15^{\circ} \mathrm{C}(37 \%)$ e, os demais regimes térmicos, conduziram as maiores porcentagens, embora não tenham diferido estatisticamente entre si. 
Com relação ao IVG (Figura 2), pode ser observado que as sementes com $51 \%$ de umidade apresentaram o menor valor a $15^{\circ} \mathrm{C}(1,07)$ e o maior a $25^{\circ} \mathrm{C}(1,52)$. Por outro lado, a $35^{\circ} \mathrm{C}(1,31)$ e $20-30^{\circ} \mathrm{C}(1,28)$ não diferiram dos demais regimes térmicos testados. Em sementes dessecadas a $13 \%$ de umidade, o menor IVG também foi a $15^{\circ} \mathrm{C}(0,86)$ e os demais regimes térmicos não diferiram estatisticamente entre si.

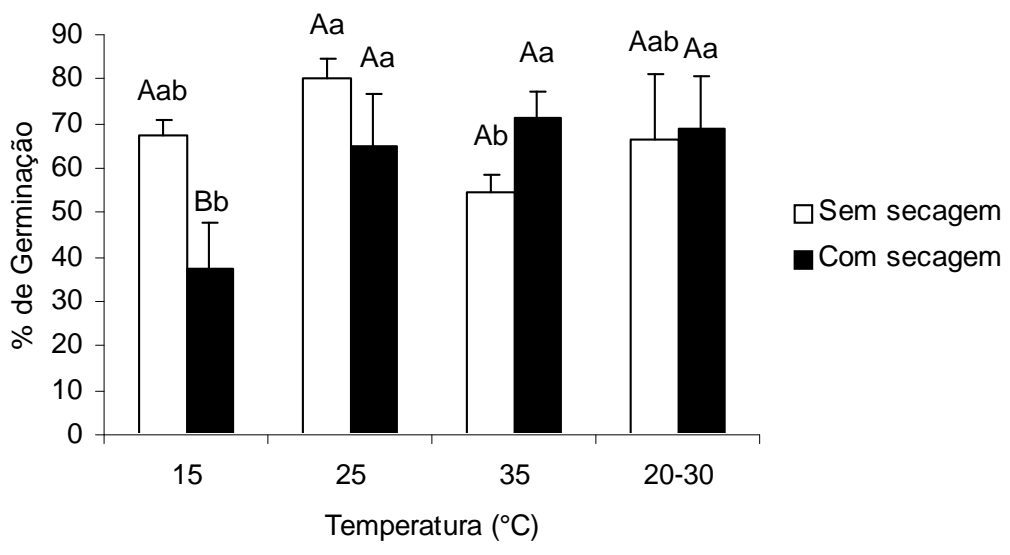

FIGURA 1 - Valores médios da porcentagem final de germinação de sementes de Protium widgrenii com 51\% de umidade e dessecadas a $13 \%$, submetidas a diferentes temperaturas. Letras maiúsculas comparam médias de germinação entre sementes não dessecadas e dessecadas, enquanto as minúsculas comparam as temperaturas. As médias seguidas pela mesma letra não diferem entre si pelo teste de Tukey, a $5 \%$ de probabilidade. CV $=16,44 \%$.

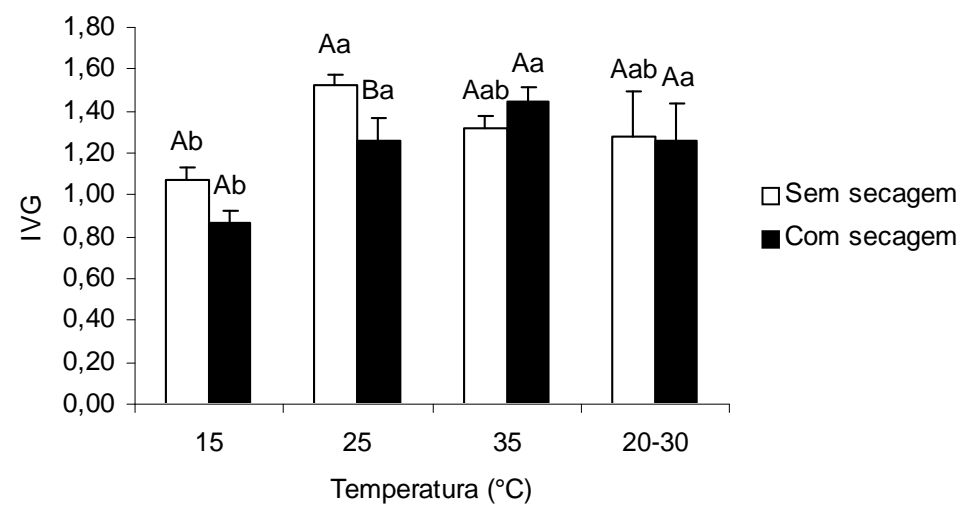

FIGURA 2 - Valores médios de Índice de Velocidade de Germinação (IVG) de sementes de Protium widgrenii com 51\% de umidade e dessecadas a $13 \%$, submetidas a diferentes temperaturas. Letras maiúsculas comparam sementes com $51 \%$ de umidade e com 13\%, as minúsculas referem-se às temperaturas em sementes dessecadas e com umidade inicial. As médias seguidas pela mesma letra não diferem entre si pelo teste de Tukey, a 5\% de probabilidade. CV =11,12\%. UFLA, 2001. 
Comparando-se a porcentagem final de germinação entre as sementes com $51 \%$ de umidade e com $13 \%$, pode-se verificar que a $15^{\circ} \mathrm{C}$ a porcentagem final de germinação foi maior em sementes não submetidas ao dessecamento. Algumas sementes, como as de Phaseolus vulgaris L. e Zea mays L., quando intensamente desidratadas são embebidas em água, podem sofrer danos irreparáveis no sistema de membranas, o que leva a lixiviação de conteúdo celular, prejudicando, conseqüentemente a germinação (CORBINEAU et al., 2000; FERREIRA \& BORGHETTI, 2004; PARMMENTER et al., 2000; WALTERS et al., 2001). Segundo Wolk et al. (1989), esses danos aumentam a baixas temperaturas. Por outro lado, quando sementes desidratadas são colocadas para germinarem em temperaturas mais elevadas, elas conseguem reorganizar mais rapidamente a estrutura das membranas, perdendo, portanto, menor conteúdo celular por lixiviação (FERREIRA \& BORGHETTI, 2004).

Quando as sementes foram dessecadas a $13 \%$ de umidade e germinadas a $25^{\circ} \mathrm{C}$, houve uma redução significativa no IVG, quando comparadas com sementes com $51 \%$ de umidade, na mesma temperatura, indicando que houve perda de vigor com a dessecação. Esse comportamento, aliado à redução na germinação a $15^{\circ} \mathrm{C}$, poderá caracterizar um comportamento tipicamente recalcitrante (FERREIRA \& BORGHETTI, 2004).

Considerando-se as diferentes temperaturas avaliadas durante o processo germinativo das sementes de Protium widgrenii, pôde-se verificar que a espécie em questão apresenta alta porcentagem de germinação e IVG a $25^{\circ} \mathrm{C}$ constante, sendo essa temperatura a mais indicada. Resultados semelhantes foram obtidos por Miranda \& Ferraz (1999), estudando o efeito de temperaturas constantes entre $10^{\circ} \mathrm{C}$ e $35^{\circ} \mathrm{C}$ sobre a germinação de sementes de Maquira sclerophylla (Ducke) C.C. Berg. Estes autores verificaram que a emissão da radícula aconteceu entre $15^{\circ} \mathrm{C}$ e $35^{\circ} \mathrm{C}$, com os maiores percentuais de germinação ocorrendo entre $25^{\circ} \mathrm{C}$ e $35^{\circ} \mathrm{C}$. Godoi \& Takaki (1996) observaram que as sementes de Cecropia hololeuca Miq apresentaram maior porcentagem final de germinação a $25^{\circ} \mathrm{C}$, havendo inibição em temperaturas superiores a $35^{\circ} \mathrm{C}$ e inferiores a $25^{\circ} \mathrm{C}$. Resultados semelhantes foram obtidos por Alvarenga Neto et al. (2003) em Acacia polyphylla DC.. Em duas espécies de Albizia, temperaturas de $20^{\circ}$ e $25^{\circ} \mathrm{C}$ proporcionaram maiores porcentagens e velocidade de germinação (TIGABU \& ODEM, 2001).

Baixas temperaturas podem não somente reduzir a porcentagem de germinação, como também retardar o processo, devido à redução das atividades enzimáticas envolvidas no metabolismo da semente (BEWLEY \& BLACK, 1994; SIMON et al., 1976). Segundo Scatena et al. (1996), a correlação positiva entre porcentagem e velocidade de germinação das sementes garante o sucesso na obtenção e no estabelecimento de novas plântulas.

Por outro lado, sob temperaturas mais altas, a velocidade de absorção de água e as atividades enzimáticas tornam-se mais elevadas, fazendo com as sementes germinem mais rapidamente (CARVALHO \& NAKAGAWA, 2000). Entretanto, podem ser prejudiciais à germinação de algumas espécies, provavelmente por causarem desnaturação de proteínas essenciais ao processo germinativo. Segundo Andrade et al. (2002), sementes de Pouteria campechiana (Kunth) Baehni submetidas a uma faixa térmica entre $15^{\circ} \mathrm{e}$ $40^{\circ} \mathrm{C}$, apresentavam menores porcentuais de germinação a temperaturas superiores a $35^{\circ} \mathrm{C}$.

Segundo Bewley \& Black (1994), sementes de diferentes espécies apresentam grande variação no comportamento quanto à temperatura de germinação, apresentando uma faixa ótima, situada entre as temperaturas da época propícia à germinação no hábitat natural (BASKIN \& BASKIN, 1992; TEKETAY, 1998; VILLALOBOS \& PELÀEZ, 2001). A variabilidade de respostas quanto ao requerimento de temperatura é um reflexo da adaptação das espécies ao ambiente de ocorrência (THOMPSON, 1970).

\section{CONCLUSÕES}

Sementes de Protium widgrenii apresentam cerca de $70 \%$ de sementes mal formadas, devendo ser consideradas apenas $30 \%$ viáveis em estudos de germinação e para a produção de mudas.

A temperatura ótima para a germinação dessa espécie, tanto em sementes com $51 \%$ de umidade quanto desidratadas a $13 \%$, foi $25^{\circ} \mathrm{C}$, proporcionando maiores porcentagens de germinação e IVG.

Sementes da espécie em estudo apresentam comportamento típico recalcitrante, pois tiveram seu porcentual de germinação e IVG reduzidos com a dessecação.

\section{REFERÊNCIAS BIBLIOGRÁFICAS}

ALVARENGA, S. Influência de diferentes teores de umidade, embalagens e ambientes sobre a preservação da viabilidade e vigor de sementes de pau-santo (Kilmeyera coriaceae Mart.). 1987. 84 f. Dissertação (Mestrado em Engenharia Florestal) - Universidade Federal do Paraná, Curitiba, 1987. 
ALVARENGA NETO, J. C.; AGUIAR, I. B.; FERREIRA, V. M. Effect of temperature and light on Acacia polyphylla DC: seed germination. Revista Brasileira de Botânica, São Paulo, v. 26, n. 2, p. 249-256, June 2003.

ANDRADE, R.; MARTINS, A. B. G.; SARZI, I. Efeito da temperatura na porcentagem de germinação de sementes de canistel (Pouteria campechiana). Revista Brasileira Fruticultura, Cruz das Almas, v. 24, n. 3, p. 622-623, dez. 2002.

BARTLETT, M. S. The square root transformation in analysis of variance. Journal Royal Statistical Society, [S.l.], v. 3, p. 68-78, 1936. Supplement.

BASKIN, J. M.; BASKIN, C. C. Role of temperature and light in the germination ecology of buried seeds of weedy species of disturbed forests: I. Labelia inflata. Canadian Journal of Botany, Ottawa, v. 70, n. 3, p. 589592, Mar. 1992.

BENVENUTI, S.; MACCHIA, M.; MIELE, S. Light, temperature and burial depth effects on Rumex obtusifolius seed germination and emergence. Weed Research, Champaign, v. 41, n. 2, Apr./June 2001.

BEWLEY, J. D.; BLACK, M. Seeds: physiology of development and germination. 2. ed. New York: Plenum, 1994. $45 \mathrm{p}$.

CARVALHO, L. M. de. Classificação fisiologica de sementes de espécies florestais quanto à capacidade de armazenamento. 2000. 97 p. Dissertação (Mestrado em Produção Florestal) - Universidade Federal de Lavras, Lavras, 2000.

CARVALHO, N. M.; NAKAGAWA, J. Sementes: ciência, tecnologia e produção. 4. ed. Jaboticabal: FUNEP, 2000. $588 \mathrm{p}$.

CASTELLANI, E. D.; AGUIAR, I. B. Seed maturation and effect of temperature regime on Trema micrantha (L.) Blume seed germination. Seed Science and Technology, Zurich, v. 29, n. 1, p. 73-82, 2001.

CORBINEAU, F. et al. Effects of dehydration conditions on desiccation tolerance of developing pea seeds as related to oligossaccharide content and cell membrane properties. Seed Science Research, [S.1.], v. 10, p. 329-339, 2000.
CORREAA, F. L. Efeito da embalagem e do ambiente de armazenamento, germinação e vigor de sementes de goiabeira (Psidium guajava L.). 1997. 57 f. Dissertação (Mestrado em Fitotecnia) - Universidade Federal de Lavras, Lavras, 1997.

FERREIRA, A. G.; BORGHETTI, F. Germinação: do básico ao aplicado. São Paulo: Artmed, 2004. 323 p.

FERREIRA, D. F. SISVAR 4.3 - Sistema de Análises Estatísticas. Lavras: UFLA, 1999.

GODOI, S.; TAKAKI, M. Germinação de sementes de Cecropia holoceuca Miq (Cecropiaceae), efeitos da luz e temperaturas. In: CONGRESSO DA SOCIEDADE BOTÂNICA DE SÃO PAULO, 11., 1996, São Carlos, SP. Resumos... São Carlos: UFSCar, 1996. v. 1, p. 50.

HERMANSEN, L. A.; DUREYEA, M. L.; WHITE, T. L. Variability in seed coatdormancy in Dimorphandra mollis. Seed Science and technology, Zurich, v. 28, n. 3, p. 567$580,2000$.

KLEIN, R. M. Contribuição ao conhecimento da flora e da vegetação do Vale do Itajaí- Santa Catarina. 1978. 112 f.Tese (Doutorado) - Universidade de São Paulo, São Paulo, 1978.

KRAAK, H. L. Physiological aspects of storage of recalcitrant seed. In: SOMÉ, L. M.; KAM, M. de. (Eds.). Tree seeds problems, with special reference to Africa. Leiden: [s.n.], 1993. p. 239-253.

KRZYZANOWISKI, F. C.; VIEIRA, R. D.; FERREIRA NETO, J. B. Vigor de sementes: conceitos e testes. Londrina: ABRATES, 1999. 218 p.

KUNDU, M.; CHANDA, S.; KACHARI, J. Germiantion and storage behavior of Phoebe goalparensis Hutch. Seeds. Seed Science \& Technology, Zurich, v. 31, n. 3, p. 659-666, 2003.

LABOURIAU, L. G.; AGUDO, M. On the physiology of seed germination in Salvia hispânica L: I. temperature effects. Anais da Academia Brasileira de Ciências, [S.l.], v. 59, p. 37-56, 1987.

LABOURIAU, L. G.; NODA, F.; BORGHETTI, F. Dependência de temperatura na germinação de sementes de Phaseolus aureus Roxb. In: CONGRESSO BRASILEIRO DE FISIOLOGIA VEGETAL, 5., 1995, Lavras, MG. Resumos... Lavras: UFLA, 1995. v. 1, p. 63. 
LORENZI, H. Árvores brasileiras: manual de identificação e cultivo de plantas arbóreas nativas do Brasil. Nova Odessa: Plantarum, 1992. 352 p.

MIRANDA, P. R. M.; FERRAZ, I. D. K. Efeito da temperatura na germinação de sementes e morfologia da plântula de Maquira sclerophylla (Ducke) C. C. Berg. Revista Brasileira de Botânica, São Paulo, v. 22, n. 2, p. 303-307, out. 1999. Suplemento.

NAIDU, C. V.; RAJENDRUDU, G.; SWAMY, P. M. Effect of plant growth regulators on seed germination of Sapindus trifoliatus Vahl. Seed Science \& Tecnology, Zurich, v. 28, n. 2, p. 249-252, 2000.

OLADIRAN, J. A.; AGUNBIADE, S. A. Germination and seedling development from pepper (Capsicum annuиm L.) seeds following sotorage in different packaging materials. Seed Science \& Technology, Zurich, v. 28, n. 2, p. 413-419, 2000 .

OLIVEIRA FILHO, A. T.; VILELA, E. A.; GAVILANES, M. L.; CARVALHO, D. A. Effects of flooding and understorey bamboos on the physiognomy and tree species composition of a tropical semideciduous forest in Southeastern Brazil. Vegetation, The Hague, v. 113, n. 1, p. 99-124, 1994.

PANDEY, H.; NANDI, S. K.; NADEEM, M.; PALNI, L. M. S. Chemical stimulation of seed germination in Aconitum heterophillum Wall. and A. balfourii Stapf.: important Himalayan species of medicinal value. Seed Science \& Tecnology, Zurich, v. 28, n. 1, p. 39-48, 2000.

PARMMENTER, N. W.; BERJAKE, P.; WALTERS, C. The Effect of drying rate on recalcitrant seeds: lethal water contents causes of damage and quantification of recalcitrance. In: BLACK, M.; BRADFORD, K. J.; VASQUEZ-RAMOS, J. (Eds.). Seed biology: advances and applications. [S.1.]: CAB International, 2000. p. 215-221.

PATANÈ, C. Influence of temperature on seed germination of a Sulla sweetvetch (Hedysarum coronarium L.) population collected in a hilly area of southern Italy. Seed Science \& Tecnology, Zurich, v. 28, n. 3, p. 887-890, 2000.

PINHO, S. Z.; CARVALHO, L. R.; DELACHIAVE, M. E. A. Embebição de sementes: limites entre as fases I e II. In: CONGRESSO BRASILEIRO DE FISIOLOGIA VEGETAL,
9., 2003, Atibaia. Brazilian Journal of Plant Physiology, São Paulo, v. 15, p. 244, 2003.

RAJPUT, A.; TIWARI, K. P. Effect of alternat chilling/ heating on germination of fresh teak (Tectona grands L. f) drups, without sscarification of felt mesocarp. Seed Science and Technology, Zurich, v. 29, n. 1, p. 56-64, 2001.

RAMOS, A. Influência de cinco tipos de embalagens na germinação e no vigor de sementes de angico Parapiptadenia rigida (Benth)Brenan, caixeta Tabebuia cassinoides (Lam.) DC e caroba - Jacaranda micrantha Cham. armazenadas em câmara fria e a temperatura ambiente. 1980. 134 f. Dissertação (Mestrado em Engenharia Florestal) - Universidade Federal do Paraná, Curitiba, 1980.

ROBERTS, E. H. Predicting the storage life of seeds. Seed Science \& Technology, London, v. 1, n. 1, p. 499-514, Jan. 1973.

SCATENA, V. L.; LEMOS-FILHO. J. P.; LIMA, A. A. A. Morfologia do desenvolvimento pós-seminal de Syngonanthus elegans e $S$. niveus (Eriocaulaceae). Acta Botânica Brasílica, São Carlos, v. 10, n. 1, p. 85-91, jan./abr. 1996.

SIMON, E. W.; MINCHIN, A.; McMENAMIN, M. M.; SMITH, J. M. The low temperature limit for seed germination. New Phytologist, Cambridge, v. 77, n. 2, p. 301-311, 1976.

SUN, W.; LIANG, Y. Discrete levels of desiccation sensitivity in various seeds as determined by thr equilibrium dehydration method. Seed Science Research, Wallingford, v. 11, p. 317-323, 2001.

TEKETAY, D. Germination of Acacia origena, A. pilispina and Pterolobium stellatum in response to different presowing seed treatment, temperature e light. Journal of Arid Environment, London, v. 38, n. 4, p. 551-560, Apr. 1998.

THOMPSON, P. A. Characterization of the germination response to temperature of species and ecotypes. Nature, London, v. 225, p. 827-831, 1970.

TIGABU, M.; ODEM, P. C. Effect of scarification, giberellic acid and temperature on seed grmination of two multipurpose Albizia species from Ethiopia. Seed Science and Technology, Zurich, v. 29 n. 1, p. 11-20, 2001. 
VARANDA, E. M. Balanço hídrico de espécies de mata secundária semidecídua: II. Endlicheria paniculata (Spreng.) Macbribe (Lauraceae), Protium widgrenii Engler (Burseraceae) e Sorocea bonplandii (Baill.) Burger, Lanj. \& Bôer (Moraceae). Boletim de Botânica, São Paulo v. 14, p. 81-89, 1995.

VARGHESE, B.; NAITHANI, S. C. Desiccation induced loss of vigouor and viability during storage in neem (Azadirachta indica A. Juss) seeds. Seed Science \& Technology, Zurich, v. 28, n. 2, p. 485-496, 2000.

VARGHESE, B.; NAITHANI, R.; DULLOO, M. E.; NAITHANI, S. C. Seed storage behaviour in Madhuca indica J. F. Gmel. Seed Science \& Technology, Zurich, v. 30, n. 1, p. 107-117, 2002.

VÁZQUEZ-YANES, C.; OROSCO-SEGOVIA, A. Fisiología ecológica de sevelhas en la Estation de Biología Tropical de "Los Tuxtlas", Vera cruz, México. Revista de Biología tropical, San José, 1987.

VILLALOBOS, A. E.; PELÁEZ, D. V. Influence of temperature and water stress on germination and establishment of Prosopis caldenia Burk. Journal of Arid Environment, London, v. 49, n. 2, p. 321-328, Oct. 2001.

WOLK, W. D.; DILLON, P. F.; COPELAND, L. F.; DILLEY, D. R. Dynamics of imbibition in Phaseolus vulgaris L. in relation to initial seed moisture content. Plant Physiology, Washington, v. 89, p. 805-810, 1989.

WALTERS, C.; PAMMENTER, N. W.; BERJAK, P.; CRANE, J. Desiccation damage, accelerated ageing and respiration in desiccation tolerant and sensitive seeds. Seed Science Research, Wallingford, v. 11, p. 135-148, 2001.

ZAR, J. H. Biostatistical analysis. 4. ed. New York: Prentice Hall, 1999. 929 p. 